\title{
Pulverization Induced Charge: In-Line Dry Coal Cleaning
}

\author{
Quarterly Report \\ July 1 - September 30, 1997
}

\author{
By \\ John M. Stencel
}

Work Performed Under Contract No.: DE-PS22-94PC94225

\author{
For \\ U.S. Department of Energy \\ Office of Fossil Energy \\ Federal Energy Technology Center \\ P.O. Box 880 \\ Morgantown, West Virginia 26507-0880 \\ By \\ Center for Applied Energy Research \\ 2540 Research Park Drive \\ Lexington, Kentucky 40511-8410
}




\section{Disclaimer}

This report was prepared as an account of work sponsored by an agency of the United States Government. Neither the United States Government nor any agency thereof, nor any of their employees, makes any warranty, express or implied, or assumes any legal liability or responsibility for the accuracy, completeness, or usefulness of any information, apparatus, product, or process disclosed, or represents that its use would not infringe privately owned rights. Reference herein to any specific commercial product, process, or service by trade

name, trademark, manufacturer, or otherwise does not necessarily constitute or imply its endorsement, recommendation, or favoring by the United States Government or any agency thereof. The views and opinions of authors expressed herein do not necessarily state or reflect those of the United States Government or any agency thereof. 


\section{Title Page}

Report Title: $\quad$ Pulverization Induced Charge: In-Line Dry Coal Cleaning

Type of Report: Q Quarterly

Reporting Period Start Date: $\quad$ 7/1/97

Reporting Period End Date: $\quad$ 9/30/97

Principal Author(s): John M. Stencel

Report Issue Date: $\quad 1 / 21 / 98$

DOE Award Number: $\quad$ DE-PS22-94PC94225 --13

Submitting Organization: $\quad$ Center for Applied Energy Research

2540 Research Park Drive

Lexington, KY 40511-8410 


\begin{abstract}
$\underline{\text { Abstract }}$
The technical feasibility of separating mineral matter and pyrite from coal as it is transported from pulverizers to burners in pulverized coal combustion units will be examined. The charge imparted on coal during pulverization and transport to pulverized coal (PC) burners in a utility boiler will be quantified. In addition to field charge measurements, an existing computational model will be extended to numerically simulate charged particle motion in a turbulent gas through an electric field. Results from the field tests and numerical modeling will be employed in design and construction of a laboratory scale pulverizer/classifier. This laboratory unit will be used to quantify the magnitude and differential charge imparted on bituminous and subbituminous coals during pulverization and classification at temperatures and with gaseous constituents typical to utility PC units. An electrostatic separator, designed for in-line operation between pulverizers and PC boilers, will be used to clean prepulverized coals. Theoretical and experimental data are to be used in preparing a preliminary design for a full-scale, (15 ton/hr) inline, electrostatic coal cleaning device. Finally, the economic potential for application to PC units will be assessed.
\end{abstract}




\section{Table of Contents}

Executive Summary 1

Introduction 2

Results and Discussion $\quad 4$

$\begin{array}{ll}\text { Conclusion } & 4\end{array}$

Appendix 1: List of publications and presentations 5 


\section{Executive Summary}

The research goal is to determine whether it is technically feasible to separate mineral matter and pyrite from coal as it is transported from pulverizers to burners in pulverized coal (PC) boilers. Specific objectives are to measure particle charge in the coal transport pipe between a utility's pulverizer and the coal burner; to develop a pilot-scale separation test platform for particle charge and coal beneficiation experiments; to extend an existing computational model to numerically simulate charged particle motion in a turbulent gas through an electric field; and to apply pilot-scale data, industrial expertise, and utility experience to prepare a preliminary design of a full-scale, dry coal electrostatic separation system.

The original project was scheduled for a 36 month duration. A 9 month no cost extension has been requested and granted, taking the total program duration to 45 months. Currently, the project is in the $41^{\text {st }}$ month of effort. Prior to the current reporting period, charge measurements and separation experiments were performed at two utilities; one burning a low-sulfur, compliance coal and the other burning a high-sulfur, non-compliance coal. Specialized particle extraction probes were fabricated for these in situ measurements.

During the on-site utility charge and separability experiments, pulverized coal was extracted from the burner pipes for further analysis and experimental work back at the CAER. A $10 \mathrm{gr} / \mathrm{min}$ batch feed analytical scale triboelectrostatic separator was used to evaluate the potential separability of the two coals. In addition, 6 other coals, which were either on site from previous research or were sent to the CAER for dry beneficiation analysis, were tested in the analytical unit. Results from these tests have been reported in the form of recovery curves. The two coals were also tested in a 4-40 kg/hr continuous feed pilot scale triboelectrostatic separator.

Concurrent with the lab testing, numerical modeling of the gas flow entering the separator was being conducted by researchers at Clarkson University. The computer model first evaluated the gas flow, then the dispersion of particles in the mixing and transition sections immediately prior to the separator. Results suggest that a properly designed inlet would lead to a roughly uniform concentration of particles entering the main separator.

An economic evaluation of the technology has been completed. Initial analyses were based on a stand-alone 2 ton/hour separation system because pricing information on most of the equipment involved was readily available. A cost estimate for building and using an in-line, dry coal separation system within the utility setting is being developed.

A $20-200 \mathrm{~kg} / \mathrm{hr}$ integrated test platform has been constructed and component shakedown tests have been completed. The continuous feed system incorporates all of the components necessary for coal preconditioning and collection of the separated fractions. Designs for the triboelectrostatic separator to be used in the integrated test platform are currently being evaluated. 


\section{Introduction}

Primarily wet, precombustion technologies are used to remove sulfur from coal before it is combusted. Establishing an efficient dry beneficiation technology for precombustion removal of sulfur and mineral matter would eliminate environmental objections to the handling and disposal of byproducts created by wet processing. Because the liberation of mineral matter and pyrite relies on particle comminution, and because the first step in pulverized coal combustion is the comminution of coal to -200 mesh, the application of dry electrostatic separation in-line between coal pulverizers and burners at coal-fired power plants could improve the environmental aspects of fossil fuel usage and the overall performance of fossil powered systems. This project will be the first to establish whether charge is imparted during pulverization and whether in-line separation can be performed.

Prior to the current reporting period, a specialized particle extraction and charge measurement device was designed and constructed. It was used to extract pulverized coal samples from burner pipes having diameters as great as $40 \mathrm{~cm}$ while simultaneously measuring the charge on the particles by application of its Faraday cage component. Charge data were automatically stored on computer discs for subsequent analyses. The pulverized coal samples, captured within filter bags inside of the Faraday cage, were weighed and subjected to proximate, ultimate and particle size analyses.

Concurrent with the on-site charge measurements, a portable, parallel plate electrostatic separator was designed and constructed for application within coal-fired power plants. Extraction of pulverized coal from burner pipes was accomplished by use of air eduction, which was the same operational procedure applied during the measurement of charge on coal particles. Removal of the positive and negative plates from the separator subsequent to an experiment enabled the collection of coal-enriched and mineral matter-enriched samples for analyses.

On-site charge measurement and separation experiments were performed at two utilities; one burning a low-sulfur, compliance coal and the other burning a high-sulfur, non-compliance coal. The average charge-per-mass on the pulverized coal particles within the burner pipes at both of these sites was measured to be near $5 \times 10^{-5} \mathrm{C} / \mathrm{kg}$. Although the design of the separator was not considered optimal with respect to the recovery of low sulfur and low mineral matter coal from the pulverized coal stream, the mineral matter removal within the low sulfur coal stream was between $20-50 \%$ with combustible recovery in the range $80-98 \%$.

A $10 \mathrm{gr} / \mathrm{min}$ analytical scale triboelectrostatic separator was used to evaluate the separability of the two coals collected at the host utility sites. In addition, 6 other coals, which were either on site from previous research or were sent to the CAER for dry beneficiation analysis, were tested in the analytical unit. Results from these tests have been reported in the form of recovery curves.

A $4-40 \mathrm{~kg} / \mathrm{hr}$ continuous feed, single stage, pilot scale triboelectrostatic separator has been fabricated and refined through extensive testing using model particle mixtures Pulverized coal particles are fed via screw feeder into a pneumatic transport line where they are charged and 
discharged into a separation chamber. The separation chamber is designed to allow for collection of two or three separate product streams. Filter systems and/or cyclones are used for disengaging the collected product streams from the transporting gas. The separation of coal, collected from the two utility sites, has subsequently been evaluated in the test rig.

Numerical modeling of the gas flow inside the separator is currently being conducted by researchers at Clarkson University. The FLUENT code is being used to simulate the gas and particle flows in the mixing chamber above the electrostatic separator section. Particles enter the mixing chamber in two opposing jets. A contracting transition section connects the mixing chamber and separator. The computer model first evaluated the gas flow, then the dispersion of particles in the mixing and transition sections. The results suggest that the mixing chamber and the contraction section would lead to a roughly uniform concentration of particles entering the main separator.

An economic evaluation of the technology has been completed. Analyses were based on a standalone 2 ton/hour separation system because pricing information on most of the equipment involved was readily available. The cost of an in-line coal cleaning system is expected to cost substantially less, on a per-ton-of-coal processed basis, due to an approximate $80 \%$ reduction in equipment needs, i.e. a majority of the equipment needed for in-line coal cleaning would already be in use at the utility site. The total coal processing cost is estimated to be $\$ 2.62 /$ ton. If a $15 \%$ contingency is added to the estimation, the cost becomes nearly $\$ 3 /$ ton. It must be remembered that this cost is for a stand-alone facility, not for a in-line separator which would be built and used for coal cleaning within a utility burner pipe. A cost estimate for building and using an in-line, dry coal separation system within the utility setting is still being developed.

A $20-200 \mathrm{~kg} / \mathrm{hr}$ integrated test platform has been designed and constructed. This system will be used to perform the final coal beneficiation tests, once the best triboelectrostatic separator design is determined. Original plans were to purchase a small scale continuous feed pulverizer, to prepare coal samples to a PC boiler feed size specification. The pulverizer was to operate on the same principle as large-scale utility pulverizers. After an exhaustive search it was determined that no such small scale pulverizer is commercially available. It was decided that rather than prepare the coal at the CAER, the pulverized coal would be collected from PC boiler burner pipes, returned to the lab in sealed 55 gallon drums, and fed into the integrated test rig. During on-site utility charge measurements, methods for collecting barrel quantities of pulverized coal from burner pipes were perfected.

The integrated system is continuously fed and incorporates all of the components necessary for coal preconditioning, triboelectrostatic beneficiation, and separated fraction collection. The system is instrumented to allow solid and gas mass balances. In addition, the temperature profile through the system can be monitored. All data will be recorded by using a computerized data acquisition system. Individual component shakedown tests have been completed. Coal tests are scheduled to begin once pilot scale evaluation of separator designs is completed. 


\section{$\underline{\text { Results and Discussion }}$}

The project progress during the current reporting period is described for each specific task in the following:

\section{Task 1. Charge Determinations}

This task has been completed and results have been presented in previous reports.

\section{Task 2. Pilot Scale Test Rig Development}

A $20-200 \mathrm{~kg} / \mathrm{hr}$ integrated test platform has been designed and constructed. Component shakedown tests have been completed. This system will be used to perform the final coal beneficiation tests, once the best triboelectrostatic separator design is determined.

A new 4-40 kg/hr pilot scale triboelectrostatic separator has been designed and constructed. This systems incorporates cylindrical geometry with advanced pneumatic and electrostatic principles to effectively separate carbon and mineral matter. Several model particle mixtures have been evaluated in the cylindrical unit. Based on the results from this unit, a multi-staged system is being designed. Once these smaller pilot scale tests are completed, a separator design for the integrated test platform will be selected and final coal beneficiation tests will commence.

\section{Task 3. Coal Separation Determinations}

Analytical scale coal separation tests have been completed and results previously reported. Discussions have been held with local utilities to supply pulverized coal for the pilot scale separation tests. The coal will be extracted from the utility burner pipes immediately after the pulverizer and will be transported in 55 gallon drum quantities back to the lab for subsequent testing.

\section{Task 4. Full-Scale Separator Design}

Conceptual flow sheet diagrams and preliminary drawings of a 20 ton/hr demonstration separation system are currently being prepared. Economic evaluations, described in Task 5, are being performed concurrently with this design phase.

\section{Task 5. Economic Evaluation}

An economic evaluation of a 2 ton/hr stand-alone dry beneficiation system was presented in the previous quarterly report. Efforts continue on the estimate for constructing and operating an inline, dry coal separation system within the utility setting.

\section{$\underline{\text { Conclusions }}$}


Results of on-site charge measurements have shown that the pulverization and pneumatic transport of coal leads to significant particle charge. On-site separation experiments and subsequent laboratory experiments have shown that this charge is sufficient for effectively separating pyrite and mineral matter from coal.

The current challenge is to develop a continuous process which could be integrated into an existing utility pulverizer setting and which is capable of handling the solids and gas loading typical of PC boiler burner pipes. Towards that goal, an integrated test platform has been constructed at the CAER and will be used to separate prepulverized coal collected from participating utilities.

\section{Appendix 1: List of publications and presentations}

H. Ban, J.L. Schaefer and J. M. Stencel, Process and Material Dependencies for dry Electrostatic Coal Cleaning, Workshop, Dry Separation Technology Development, 3/14/95, Lexington, KY.

J. L. Schaefer, H. Ban, K. Saito, J.M. Stencel, Quantifying Pulverizer Induced Charge in a Utility Boiler, Twelfth Annual International Pittsburgh Coal Conference, Pittsburgh, PA, 9/11-15, 1995.

J.M. Stencel, H. Ban, J.L. Schaefer and J.C. Hower, Partitioning and Behavior of Coal Macerals During Dry Coal Cleaning, Proc., Eighth International Conf. Coal Science (ICCS), 9/10-15, 1995, Oviedo, Spain, Vol. 2, pp. 1549-1552.

J. Hower, H. Ban, J.L. Schaefer, J.M. Stencel, Maceral/Microlithotype Partioning Through Triboelectrostatic Dry Coal Cleaning, meeting of the Society of Organic Petrologists, Houston, TX, Aug 28-29, 1995.

H. Ban, T.-X. Li, J.L. Schaefer, J.M. Stencel, Characterizing Dry Triboelectrostatic Beneficiation of Coal using Recovery Analysis, Thirteenth Annual International Pittsburgh Coal Conference, Pittsburgh, PA, 9/3-7, 1996.

J.L. Schaefer, H. Ban, K. Saito, J.M. Stencel, Pulverizer Induced Charge: Comparison of Separate Utility Pulverizer Configurations, Thirteenth Annual International Pittsburgh Coal Conference, Pittsburgh, PA, 9/3-7, 1996.

Fundamentals of Triboelectrostatic Separation: A Discussion on Particle Charge, Particle Size and Separation, SME Annual Meeting \& Exhibit, Denver CO, 1997.

J.M. Stencel, J.L. Schaefer, J.K. Neathery, H. Ban, T.-X. Li, In-Line Coal Cleaning:

Triboelectrostatic Separation of Coal and Mineral Matter, 9th International Conference on Coal Science, Essen, Germany, September 7-12, 1997. 
J.M. Stencel, J.L. Schaefer, H. Ban, T.-X Li, J.K. Neathery, Triboelectrostatic Cleaning of Coal In-Line between Pulverizers and Burners at Utilities, submitted to Coal Preparation Journal.

J.M. Stencel, J.L. Schaefer, H. Ban, T.-X. Li and J.K. Neathery, Mineral Matter Refection In-line Between Pulverizers and Burners at a Utility, Engineering Foundation Conference - Impact of Mineral Impurities in Solid Fuel Combustion, 11/2-7/97, Kona, Hawaii. 